\title{
Distribution and chromosomal variation in the scincid lizard genus Lygosoma (Reptilia: Squamata) in Thailand
}

\author{
Varanya Aranyavalai $^{{ }^{*}}$, Kanok Lertpanich $^{2}$, Warawut Chulalaksananukul $^{3}$ \\ ${ }^{1}$ Department of Biology, Faculty of Science, Chulalongkorn University, Bangkok, Thailand; \\ *Corresponding Author: varanya.a@chula.ac.th \\ ${ }^{2}$ Department of Agricultural Technique, Faculty of Agricultural Development and Resources Management, King Mongkut’s Institute \\ of Technology Ladkrabang, Bangkok, Thailand \\ ${ }^{3}$ Department of Botany, Faculty of Science, Chulalongkorn University, Bangkok, Thailand
}

Received 15 July 2013; revised 15 August 2013; accepted 22 August 2013

Copyright (C 2013 Varanya Aranyavalai et al. This is an open access article distributed under the Creative Commons Attribution License, which permits unrestricted use, distribution, and reproduction in any medium, provided the original work is properly cited.

\begin{abstract}
The distribution of the scincid lizard genus $L y$ gosoma in Thailand was studied and recorded on a map. In addition, the studies on chromosomes of Lygosoma bowringii, L. khoratense and $L$. quadrupes were examined. The karyotype was determined for each individual on the basis of at least 10 well spread cells. $L$. bowringii and $L$. khoratense showed the same diploid number of $2 \mathrm{~N}=32$ and identical chromosome morphology. The fundamental number (N.F.) equals 48. The karyotype of $L$. quadrupes is almost identical to that of $L$. bowringii, but differs from the latter in having a telocentric pair 9. Thus, the N.F. value equal to 46 . No sex chromosome heteromorphisms is evident.
\end{abstract}

Keywords: Distribution; Chromosome; Skinks; Lygosoma; Thailand

\section{INTRODUCTION}

Skinks are a hyper-diverse group of reptiles, containing more than 1000 species ranging from temperate to tropical regions on all continents but Antarctica [1,2]. Of these, about 12 genera are recognized in Thailand [3] and probably some skinks are waiting for description. The genus Lygosoma described by Hardwicke \& Gray, 1827 in family Scincidae has a long and complicated nomenclatural history. The common name, writhing skinks, refers to the way these stubby-legged animals move, snakelike but slower and more awkward. The limbs are partially or almost completely reduced (varying from com- pletely developed four or five digital to hardly noticeable unidactylous or adactylous limbs). They are truly cosmopolitan, distributed in Africa, Australia, South and Southeast Asia, Polynesia, and Central America. These skinks are seldom seen on the surface of the soil or leaf litter. Lygosoma feeds on insects and small invertebrates. Most species lay eggs, but a few are live-bearers. Very few record of this genus was subsequently made, and our knowledge about this secretive skink and its geographical distribution remains minimal. Currently, most of the skink's data are focused on taxonomic status. There are very few records of biology of skinks, making it difficult to available in applied works such as concentrating on captive breeding, and conserving skink species of pure genetic quality. Cytotaxonomic studies are especially meager, despite their possible great contributions to the understanding of the divergence and relationships of the species. This is due to the paucity of chromosomal data, especially for the species of Lygosoma. The aim of this research is to study species distribution, chromosome number and describe karyotypes of the scincid genus $L y$ gosoma in Thailand. Results revealed the presence of considerable intraspecific chromosomal variations within the genus.

\section{MATERIALS AND METHODS}

Field surveys were conducted in Thailand, including Bangkok, Phra Nakhon Si Ayutthaya, Nakhon Nayok, Chai Nat, Nakhon Sawan, Uttaradit, Phetchabun, Phichit, Kamphaeng Phet, Tak, Sukhothai, Phrae, Lampang, Lamphun, Nan, Chiang Mai, Mae Hong Son, Chiang Rai, Saraburi, Nakhon Ratchasima, Burirum, Khon Kaen, Ubon Ratchathani, Nongkhai, Nakhon Phanom, Suphan- 
buri, Kanchanaburi, Chachoengsao, Rayong, Chanthaburi, Chumphon, Ranong, Suratthani, Nakhon Si Thammarat, Phatthalung, Songkhla, Phang-nga, Krabi, Phuket, Trang and Satun provinces. Specimens were collected by pitfall traps and using the visual encounter survey method. Detailed localities of Lygosoma were recorded and plotted in a map. Specimens of Lygosoma bowringii, $L$. khoratense, and L. quadrupes were karyotyped in the laboratory. They were injected intraperitoneally with $0.1 \mathrm{ml}$ of colchicines solution $(2 \mathrm{mg} / \mathrm{ml})$ per gram body weight, $16 \mathrm{hr}$ before being sacrificed. Metaphase mitotic cells taken from femur bone marrow were treated with $0.075 \mathrm{M}$ hypotonic KCL solution for approximately $30 \mathrm{~min}$, followed by fixation in 1:3 glacial acetic acid:absolute methyl alcohol. Mitotic chromosome preparations were made by an air-dry method and stained in $10 \%$ Giema solution for $10-15$ min. The karyotype was determined from at least 10 well-spread cells. Terminology for chromosomal description follows Green and Sessions [4]. The experimental protocol was approved by the Animal Care and Use Committee of Faculty of Science, Chulalongkorn University (Protocol Review No. 0923003).

\section{RESULTS}

\subsection{Distribution}

Three species of skinks in genus Lygosoma, including $L$. quadrupes, $L$. bowringii, and $L$. khoratense were found at 28 locations during the field surveys. Localities of them were shown in Figure 1 and Table 1.

\subsection{Description of Species}

\section{Lygosoma quadrupes}

A slender and very elongate skink with four very short limbs but still has five digits. The ear-opening is very small, narrow and partly covered with scales. The lower eyelid is nearly yellow-white, movable and covered by two rows of small scales. There is a single frontoparietal and nasal but the postnasal is absent. The rostral is little wider than high, while the frontonasal is broader than long, forming suture with rostral, frontal, and anterior loreal. The anterior loreal is higher but narrower than the second loreal. The prefrontals are small and widely separated. The frontal is little longer than its distance from tip of snout, about as long as single frontoparietal, but smaller. The interparietal is little smaller than frontal and enclosed by parietals. There are 24 to 26 scalerows around middle of body. The color is gray-brown to brown with dark longitudinal lines, usually visible on edges of all scalerows, continued onto tailed. The top of head is darker than the body (Figures 2(a) and (b)).

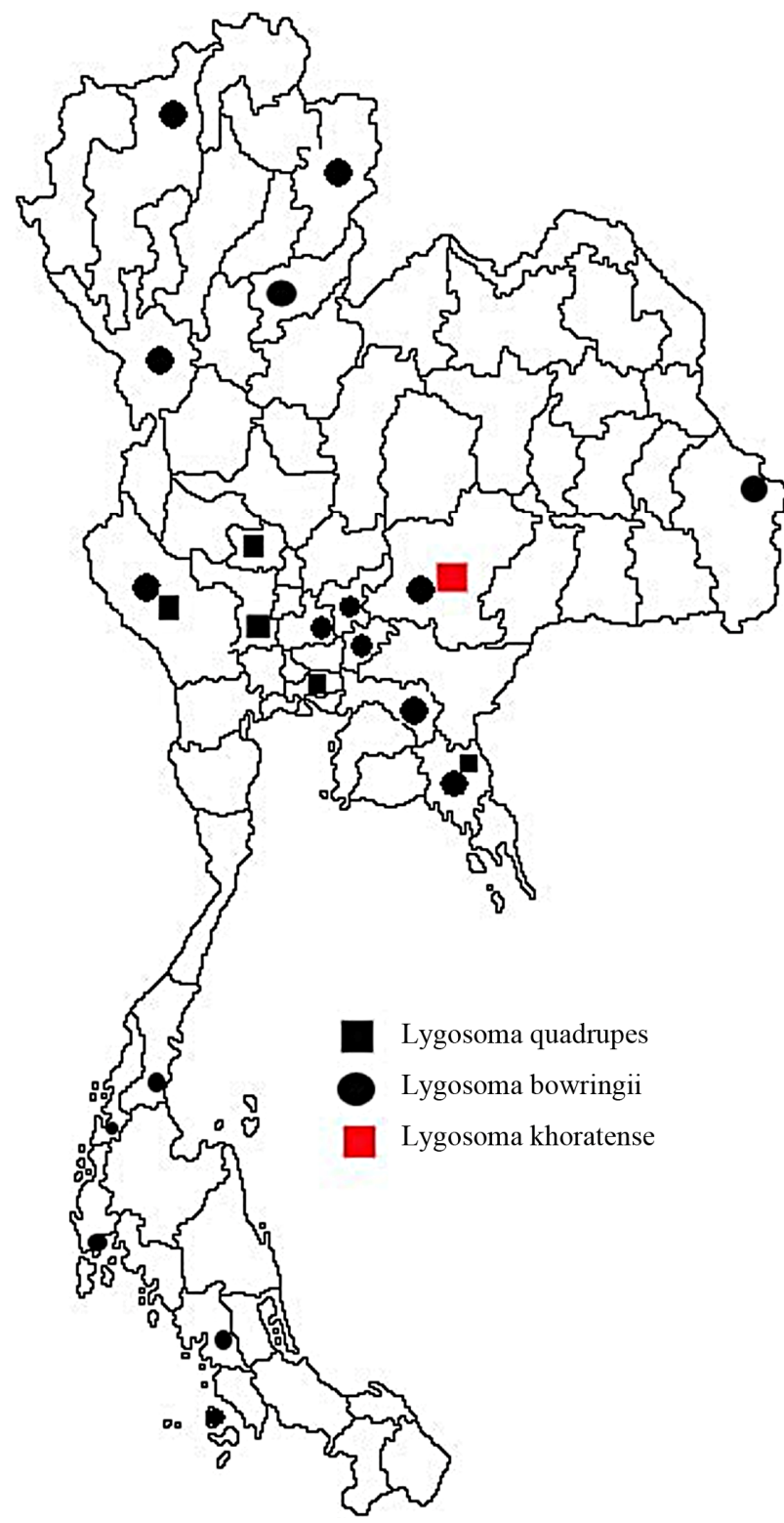

Figure 1. Distribution of Lygosoma quadrupes, L. bowringii, and L. khoratense in Thailand.

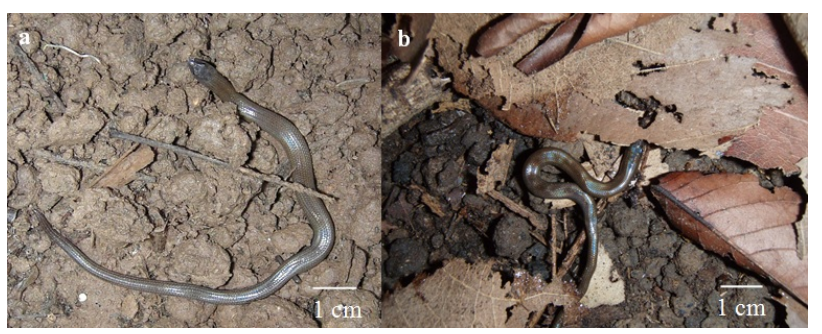

Figure 2. Lygosoma quadrupes (a) from Kanchanaburi Province; (b) from Chai Nat Province.

\section{Lygosoma bowringii}

A little skink with short limbs and cannot touch unless the body is flexed. The small supranasal scales are pre- 
Table 1. Locations of skinks in genus Lygosoma observed in the field surveys.

\begin{tabular}{|c|c|c|c|}
\hline Species & No. & Province & Location \\
\hline \multirow{6}{*}{ Lygosoma quadrupes } & 1 & Bangkok & Pramongkutklao Hospital and College of Medicine \\
\hline & 2 & Bangkok & King Mongkut's Institute of Technology Ladkrabang \\
\hline & 3 & Chai Nat & Amphoe Mueang \\
\hline & 4 & Chanthaburi & Amphoe Kaeng Hang Maeo \\
\hline & 5 & Suphanburi & Amphoe Song Phi Nong \\
\hline & 6 & Kanchanaburi & Amphoe Thong Pha Phum \\
\hline \multirow{21}{*}{ Lygosoma bowringii } & 7 & Phra Nakhon Si Ayutthaya & Amphoe Mueang \\
\hline & 8 & Nakhon Nayok & Wangtakrai, Amphoe Mueang \\
\hline & 9 & Uttaradit & Amphoe Laplae \\
\hline & 10 & Tak & Amphoe Sam Ngao \\
\hline & 11 & Nan & Amphoe Wiang Sa \\
\hline & 12 & Chiang Mai & Amphoe Fang \\
\hline & 13 & Kanchanaburi & Amphoe Thong Pha Phum \\
\hline & 14 & Chachoengsao & Amphoe Sanam Chai Khet \\
\hline & 15 & Chachoengsao & Amphoe Tha Takiap \\
\hline & 16 & Chanthaburi & Amphoe Kaeng Hang Maeo \\
\hline & 17 & Chanthaburi & Amphoe Khlung \\
\hline & 18 & Chanthaburi & Amphoe Laem Sing \\
\hline & 19 & Chanthaburi & Amphoe Soi Dao \\
\hline & 20 & Saraburi & Amphoe Kaeng Khoi \\
\hline & 21 & Nakhon Ratchasima & Amphoe Sikhio \\
\hline & 22 & Ubon Ratchathani & Amphoe Khong Chiam \\
\hline & 23 & Chumphon & Amphoe Phato \\
\hline & 24 & Ranong & Amphoe Kapoe \\
\hline & 25 & Phang-nga & Amphoe Ко Yао \\
\hline & 26 & Trang & Amphoe Na Yong \\
\hline & 27 & Satun & Amphoe La-ngu \\
\hline Lygosoma khoratense & 28 & Nakhon Ratchasima & Amphoe Sikhio \\
\hline
\end{tabular}

sent and the tympanum is deeply sunk below the external ear opening. The frontonasal is large, laterally touching the first loreal. The prefrontals are widely separated and the suture between frontal and frontonasal is nearly a straight line. The length of frontal is greater than its distance from tip of snout but less than length of combined parietals and frontoparietals. The frontoparietal is divided and the interparietal is enclosed by parietals. There are two loreals, anterior higher and narrower than the second. It has smooth or faintly keeled scales, a scaled lower eyelid, and a distinctive dark flank band with white spots, red behind the arm and yellow bellow. There are 30 scalerows around neck and 31 scalerows around middle of body. The ventral scales are larger than the laterals but smaller than the dorsals (Figures 3 (a) and (b)).

\section{Lygosoma khoratense}

An elongate skink with small widely separated pentadactyl limbs. The rostral is wider than high and part visible above considerably is longer than suture between supranasals. The latter scales are fused to the nasals anteriorly. The frontonasal is about twice as broad as long touching the first loreal. The prefrontals are small and widely separated, leaving a broad suture between frontal and frontonasal. The first loreal is higher and shorter than the second. The frontoparietal are paired. The interparietal is small, enclosed behind by parietals. The ear-opening is very small with small lobules projecting from anterior border. Snout scales are somewhat thickened. There

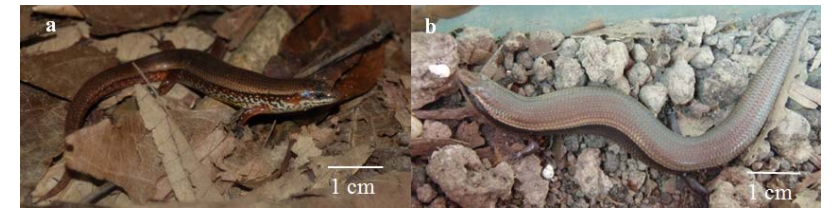

Figure 3. Lygosoma bowringii (a) from Satun Province; (b) from Chanthaburi Province.

are 28 scalerows around neck and 32 to 34 scalerows around middle of body. The short thick tail suddenly tapers at the tip. The dorsum is brownish, each scale with a dark brown edge and a vague dark spot at its base. The flanks are lighter than the dorsum while the venter is pale grey, and the subcaudals are darker. The scales of head are slightly darker edges. It is found only in Thailand.

\subsection{Chromosome Numbers and Karyotypes}

Karyotypes of Lygosoma bowringii and L. khoratense seem to be identical with each other when treated with Giemsa: both species have $2 \mathrm{~N}=32$ chromosomes forming three size groups (Figures $\mathbf{4 ( a )}$ and (b)). Of these, pairs 1 to 4, composing the largest group, are metacentric macrochromosomes. There is a size discontinuity between pairs 4 and 5 . The second size group consists of four pair metacentric chromosomes (pairs 5, 6, 7, and 9), gradually reducing in size. Of the remainder composing the smaller size, pair 8 is submetacentric, whereas the smallest 


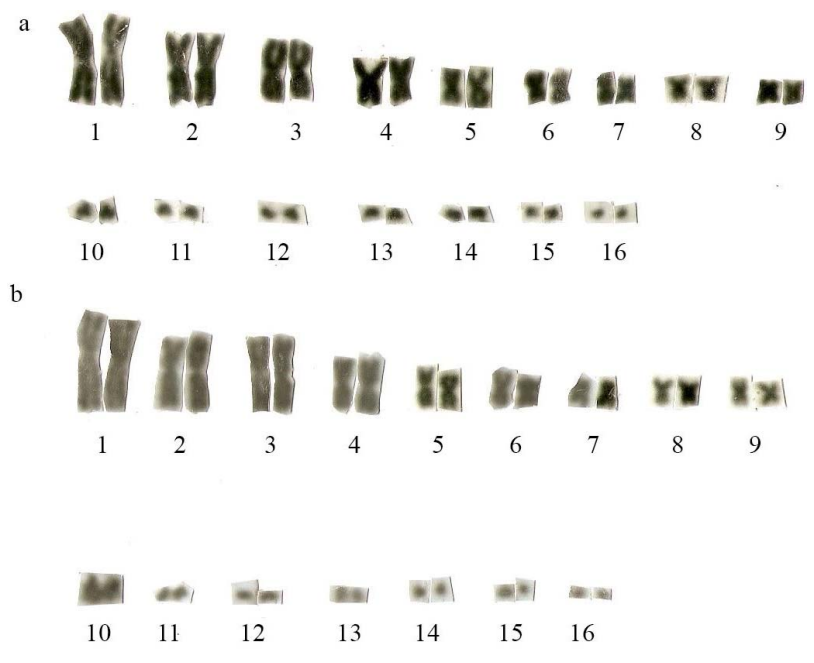

Figure 4. Karyotypes of (a) Lygosoma bowringii (male) from Chanthaburi Province, and (b) Lygosoma khoratense (male) from Nakhon Ratchasima Province. Bar equals $10 \mu \mathrm{m}$.

pair appears to be telocentric. The fundamental number (N.F.) is calculated as 48. The karyotype of $L$. quadrupes (Figure 5) is almost identical to that of $L$. bowringii and L. khoratense, but differs from the latter in having a telocentric pair 9. Thus, the N.F. value equals 46 . In addition, in these three Lygosoma species, secondary constrictions are evident on the shorter arms of pair 1 or the longer arms of pair 2 or both. No sex chromosome heteromorphisms are evident.

\section{DISCUSSION}

During our field surveys, three species of skinks in genus Lygosoma were found. The microhabitats of them are cryptozoic and partially fossorial and are found under dead tree trunks, in dead wood and in loose, humid soil where they glide with agility. L. bowringii, L. khoratense and $L$. quadrupes hitherto examined have karyotypes sharing many similarities with each other such as the diploid chromosome number (32), large metacentricity in pairs 1 to 4 and the distinct size-gap between pairs 4 and 5 . So, these populations seem to be lacking in chromosome changes that could act as reproductive barriers. However, because speciation in lizards is not always associated with chromosome repatterning (see [5] for review), and considering that the $2 \mathrm{~N}=32$ karyotype is plesiomorphic for skinks [6], the lack of karyotypic differentiation does not necessarily indicate that the " $L$. bowringii" and " $L$. khoratense" forms belong to the same biological species. Therefore, further C-banding studies are needed for the inference of its derivation process. In addition, future detailed analyses involving karyotypes of the remaining species in genus Lygosoma are needed to test in order to clarify intraspecific chromosomal variations within this genus.

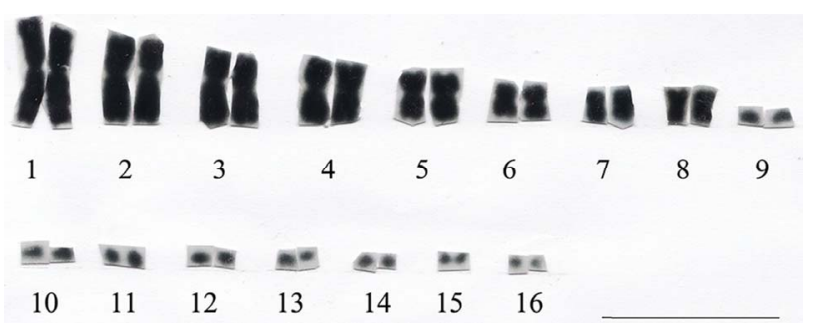

Figure 5. Karyotype of Lygosoma quadrupes (male) from Chainat Province. Bar equals $10 \mu \mathrm{m}$.

\section{CONCLUSION}

This study reported the distribution of the scincid lizard genus Lygosoma in Thailand. Comparison on chromosomes of Lygosoma bowringii and L. khoratense showed the same diploid number of $2 \mathrm{~N}=32$ and identical chromosome morphology. The karyotype of L. quadrupes is almost identical to that of $L$. bowringii, but differs from the latter in having a telocentric pair 9 . There is no evidence of heteromorphic sex chromosomes.

\section{ACKNOWLEDGEMENTS}

This research was supported by the TRF/BIOTEC Special Program for Biodiversity Research and Training Grant (Grant no. MRG 5080366). Varanya is also indebted to Dr. Ratchata Phochayavanich, Mr. Chattraphas Pongchareon, and Mr. Kasem Theingtham for helping with field sampling.

\section{REFERENCES}

[1] Matsui, M. (1992) Systematic zoology, Vol. 9, vertebrates IIb2, Reptilia II. Nakayama-Shoten, Tokyo.

[2] Zug, G.R., Vitt, L.J. and Caldwell, J.P. (2001) Herpetology. Academic Press, London.

[3] Nabhitabhata, J., Chanard, T. and Chuaynkern, Y. (2000) Checklist of amphibians and reptiles in Thailand. Office of Environmental Policy and Planning Bangkok, 80-92.

[4] Green, D.M. and Sessions, S.K. (1991) Nomenclature for chromosomes. In: Green, D.M. and Sessions, S.K., Eds., Amphibian Cytogenetics and Evolution, Academic Press, San Diego, 431-432.

[5] King, M. (1981) Chromosome change and speciation in lizards. In: Atchley, W.R. and Woodruff, D.S., Eds., Evolution and Speciation, Cambridge University Press, Cambridge, 262-285.

[6] Caputo, V., Odierna, G. and Aprea, G. (1994) A chromosomal study of Eumeces and Scincus, primitive members of the Scincidae (Reptilia, Squamata). Bolletino di Zoologia, 61, 155-162. doi:10.1080/11250009409355876 